\title{
Climatology of aerosol radiative properties over East Asia in spring
}

\author{
Na Kang, Jia Ma, Xingna Yu, Zhiyuan Mao \\ Key Laboratory of Meteorological Disaster of Ministry of Education, Department of Atmospheric Physics, \\ Nanjing University of Information Science and Technology, \\ Nanjing, China \\ nameir@126.com
}

\begin{abstract}
The knowledge of aerosol properties on a regional scale is important in understanding of the global climate change and radiation forcing. In order to understand aerosol radiative properties in East Asia, 8-year measurements were conducted during 2001-2008. In this study, the aerosol radiative properties over East Asia in spring have been presented from the Aerosol Robotic Network (AERONET) measurements. The average single scattering albedo $(\omega)$ showed a wild increasing trend with wavelengths for Dunhuang sites and a low sensitivity to wavelengths for others sites. The $\omega$ varied in the range of 0.925 0.975 at Dunhuang, 0.885-0.916 at Beijing and Seoul, and 0.9120.944 at Gosan, Osaka and Noto at 440, 675, 870 and $1020 \mathrm{~nm}$. The averages of asymmetry factor $(\mathrm{g})$ were found to be larger at Dunhuang compared to other five sites. The increase of asymmetry factor was possibly attributed to the higher contribution of large particle, and indicated the particles over dust source regions were predominant in forward scattering. The averages of $g$ at the four wavelengths were 0.72 in Dunhuang, 0.67 in Gosan and Noto, and 0.66 in three urban sites (Beijing, Seoul and Osaka).
\end{abstract}

\section{Keywords-aerosol; dust; radiative propertiy; East Asia}

\section{INTRODUCTION}

It is well known that aerosols can impact on the global and regional climate, both by directly interacting with solar radiation and by indirectly modifying cloud microphysics ${ }^{[1-3]}$. Estimates of aerosol direct radiative forcing due to anthropogenic aerosols ranged from -0.9 to $-0.1 \mathrm{~W} \mathrm{~m}-2^{[4]}$. It is noted that aerosol-induced radiative forcing still contain considerable uncertainties due to the poor understanding of aerosol properties and significant regional variability.

East Asia is a major source region of combustion-related anthropogenic pollutants as well as mineral dust aerosols. Asian dust rising from the dust storms that occur in the arid regions of China and Mongolia, is easily transported over thousands of kilometers during the spring by the westerlies, and can be transported to large part of northern China, Korea, Japan and even the west of America across the North Pacific Ocean ${ }^{[5-9]}$. In order to better understand the variation of radiative properties of aerosol particle during the long-range transport process, we need to characterize the climatology of aerosol radiative properties and analyze their spatial variability over East Asia using simultaneous data sets of six AERONET sites in China, Korea and Japan during 2001-2008.

\section{MEASUREMENT}

We selected the data acquired at the six sites of China, Korea and Japan to study the variation of aerosol properties in spring of East Asia. Dunhuang site is located at the west of Hexi Corridor and is viewed as one strong dust activity center in northwest China. Beijing, the capital of China, is located at the northwestern border of the Great North China Plain. Seoul is a big city with a large population, lots of traffic, and is heavily influenced by industry from the surrounding regions. This instrument is installed on the campus of Seoul National University in the southern part of Seoul, Korea.The Gosan site is located on Jeju Island and is considered as an ideal location to monitor the regional background atmosphere in the East Asia regions because there are no local industrial sources ${ }^{[10,11]}$. Osaka is located on the southwest of the Honshu Island which is the largest island of Japan. Noto is located in Noto peninsula of Ishikawa-gun. The exact locations of these six sites are given in Table 1 and Figure 1.

All of measurements reported in this paper were made with sun/sky autonomous radiometers which are a part of the AERONET global network. The Aerosol Robotic Network (AERONET) is an optical ground-based aerosol monitoring network and data archive. Sun and Sky measurements were performed in seven spectral bands $(340,380,440,500,670$, 870 and $1020 \mathrm{~nm}$ ), from which the aerosol content, size distribution and single scattering albedo were derived. The 940 $\mathrm{nm}$ channel is used to estimate the water vapor content. The total uncertainty in the optical thickness was around 0.01 . The uncertainty in the sky radiance measurements was assumed to be $< \pm 5 \%$ for all channels at the time of calibration. The uncertainties in the size distribution and refractive index values retrieved from AERONET data are discussed by Dubovik et al. ${ }^{[12]}$. Detailed description of the instruments and data acquisition procedure was given by Holben et al. ${ }^{[13]}$. Data sets used in this study were the AERONET level 2.0 data fully cloud-screened, calibrated and verified by the method of Smirnov et al. ${ }^{[14]}$.

\section{RESULTS}

\section{A. Single scattering albedo}

The single scattering albedo $(\omega)$ represents a key parameter in describing the aerosol radiative properties. The $\omega$ describes the relative contribution of absorbing to extinction and is a key 
variable in assessing the climatic effects of aerosols. Theoretically, the values of $\omega$ can vary between 0 (totally absorbing aerosol) and 1 (totally scattering aerosol). Actual SSA values are ranging from 0.5 to 1.0 in the visible and UV wavelengths.

Figure 2 shows the average single scattering albedos over Dunhuang, Beijing, Gosan, Seoul, Osaka and Noto at 440, 675, 870 and $1020 \mathrm{~nm}$ during the experiment period, in which the albedos have been averaged over all individual single scattering albedo. The $\omega$ almost showed a low sensitivity to wavelengths, with a range of 0.925-0.975 at Dunhuang, 0.8850.916 at Beijing and Seoul, and 0.912-0.944 at other sites at the four wavelengths. For Dunhuang sites, the single scattering albedo showed a wild increasing trend with wavelengths, the averages were 0.925 at $440 \mathrm{~nm}$ and 0.972 at latter three wavelengths. The calculation of Tanré et al. ${ }^{[15]}$ indicated that the values of $\omega$ varied from 0.95 to 0.97 during $440-1020 \mathrm{~nm}$ at
Banizoumbou site of Africa. Kim et al. ${ }^{[16]}$ reported that the average of $\omega$ at $550 \mathrm{~nm}$ yielded 0.95 in April of 2001 at Yulin, and 0.91 during a dust episode of 10-13 in April of 2001 at Gosan. Compared to Dunhuang near dust source regions, the reduction in $\omega$ at other sites especially in Beijing and Seoul was due to the addition of fine pollution particles in metropolitan areas.

\section{B. Asymmetry factor}

The asymmetry parameter is a measure of the preferred scattering direction (forward or backward) for the light encountering the aerosol particles. In radiative transfer studies,

$$
\mathrm{g}=\frac{1}{2} \int_{-1}^{+1} \mu P(\mu) d \mu
$$

TABLE 1 Location of AERONET sites selected for the present study in East Asia

\begin{tabular}{|c|c|c|c|c|c|}
\hline Country & Sites & Latitude & Longitude & Elevation (m) & Period \\
\hline \multirow[t]{2}{*}{ China } & Dunhuang & $\mathrm{N} 40.038^{\circ}$ & E 94.794 & 1300 & 2001 \\
\hline & Beijing & N $39.977^{\circ}$ & E $116.381^{\circ}$ & 92 & 2001-2007 \\
\hline \multirow[t]{2}{*}{ Korea } & Gosan & $\mathrm{N} 33.292^{\circ}$ & E $126.161^{\circ}$ & 72 & 2001-2004, 2006 \\
\hline & Seoul & $\mathrm{N} 37.458^{\circ}$ & E $126.951^{\circ}$ & 116 & 2002 \\
\hline \multirow[t]{2}{*}{ Japan } & Osaka & $\mathrm{N} 34.651^{\circ}$ & E $135.591^{\circ}$ & 50 & $2002,2004,2007$ \\
\hline & Noto & $\mathrm{N} 37.334^{\circ}$ & E $137.137^{\circ}$ & 200 & $2001,2003,2008$ \\
\hline
\end{tabular}

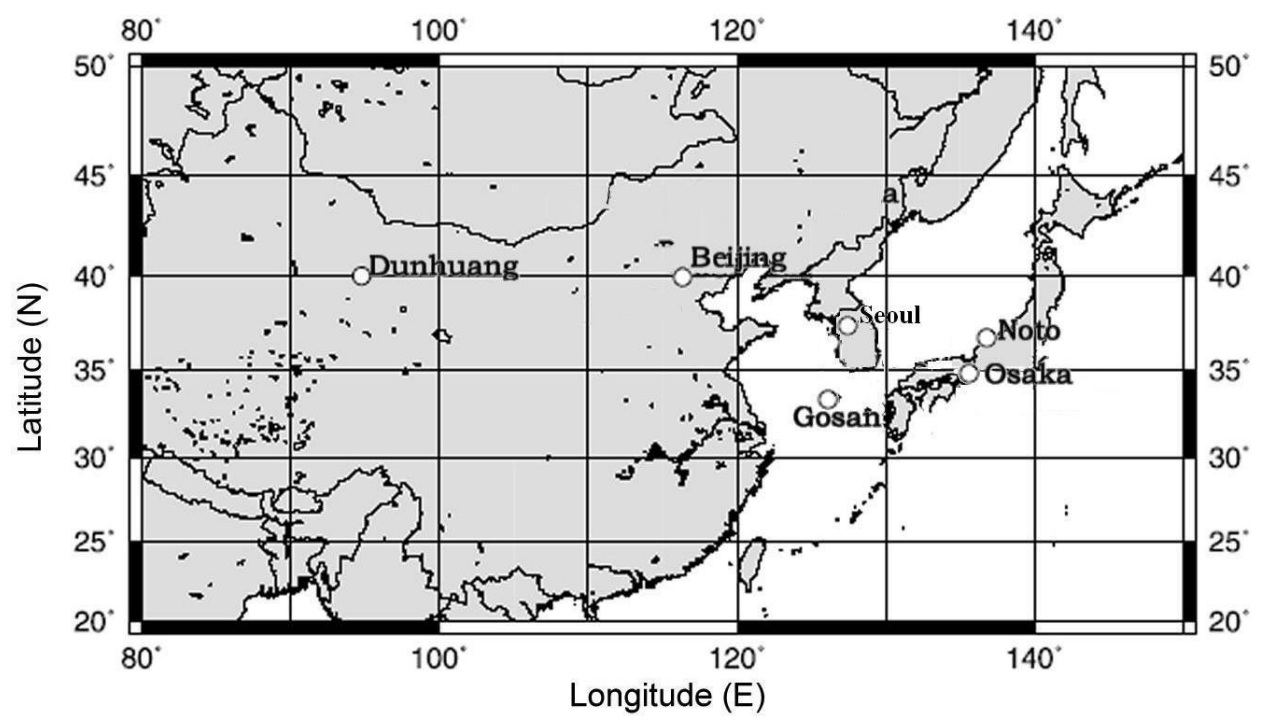

Fig. 1. Location of Dunhuang, Beijing, Gosan, Seoul, Osaka and Noto in East Asia. 
$\mu$ is the cosine of the scattering angle, $\mathrm{P}(\mu)$ is the angular scattering phase function. The asymmetry factor $(g)$ approaches +1 for scattering strongly peaked in the forward direction and 1 for scattering strongly peaked in the backward direction. In general, $\mathrm{g}=0$ indicates scattering directions evenly distributed between forward and backward directions, i.e isotropic scattering (e.g scattering from small particles). For larger size or Mie particles, $g$ is close to +1 .

The averages of asymmetry factor at 440, 675, 870 and $1020 \mathrm{~nm}$ over six sites during the experiment period are shown in Figure 3, in which the factors have been averaged over all individual asymmetry factor. The values of $g$ almost decreased at $440-870 \mathrm{~nm}$ and then increased at $870-1020 \mathrm{~nm}$ at all sites. This result was similar to the observation obtained by $\mathrm{Yu}$ et al. ${ }^{[17]}$ at Beijing, Gwangju, Shirahama and Noto sites during the dusty days. The averages of $g$ were found to be larger at Dunhuang compared to other five sites, and varied in the range of $0.718-0.745$ at the four wavelengths. The increase of asymmetry factor was possibly attributed to the higher contribution of large particle, and indicated the particles over dust source regions were predominant in forward scattering. The averages of asymmetry factor in the four wavelengths were 0.72 in dust source site (Dunhuang), 0.67 in two coastal sites (Gosan and Noto), and 0.66 in three urban sites (Beijing, Seoul and Osaka).

\section{CONCLUSION}

The single scattering albedo $(\omega)$ and asymmetry factor (g) in East Asia were presented using the data of solar direct and sky radiance measurements from 2001 to 2008. The single scattering albedo alomost showed a low sensitivity to wavelengths and vaieded from 0.925 to 0.975 at Dunhuang, in the range of 0.885-0.916 at Beijing and Seoul, and 0.912-0.944 at Gosan and Japanses sites at the four wavelengths. Compared to Dunhuang near dust source regions, the reduction in $\omega$ at

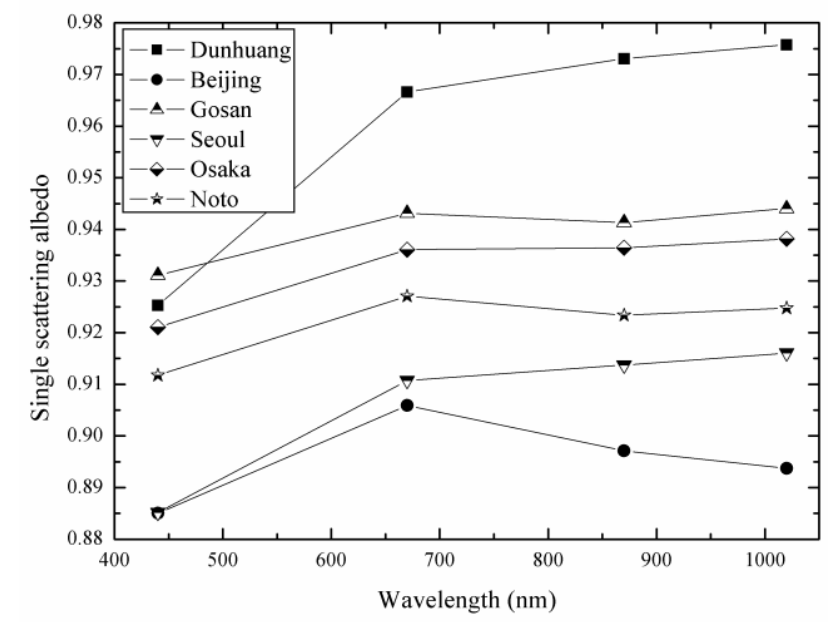

Fig. 2. The average single scattering albedos over Dunhuang, Beijing, Gosan, Seoul, Osaka and Noto at 440, 675, 870 and $1020 \mathrm{~nm}$ from 2001 to 2008, in which the albedos have been averaged over all individual single scattering albedo.

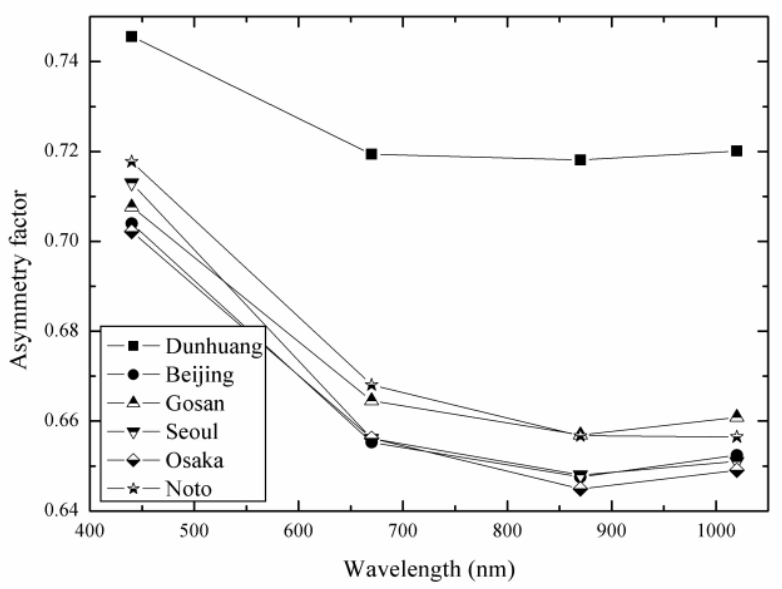

Fig. 3. The averages of asymmetry factor at 440, 675, 870 and $1020 \mathrm{~nm}$ over Dunhuang, Beijing, Gosan, Seoul, Osaka and Noto at 440, 675, 870 and 1020 $\mathrm{nm}$ from 2001 to 2008 , in which the factors have been averaged over all individual asymmetry factor.

other sites especially in Beijing and Seoul was due to the addition of fine pollution particles in metropolitan areas. The averages of $g$ were found to be larger at Dunhuang compared to downwind sites, and the increase of asymmetry factor was possibly attributed to the higher contribution of large particle. The averages of asymmetry factor in the four wavelengths were 0.72 in Dunhuang, 0.67 in two coastal sites (Gosan and Noto), and 0.66 in three urban sites (Beijing, Seoul and Osaka).

\section{ACKNOWLEDGMENT}

This work was supported by the Key Laboratory of Meteorological Disaster of Ministry of Education, Nanjing University of Information Science and Technology (No. KLME1003), the National Natural Science Foundation of China (No.41275128) and National Undergraduate Training Programs for Innovation and Entrepreneurship (No. 201210300021). We thank Holben B., Chen H., Yoon S., Sano I. and their effort for establishing and maintaining Dunhuang, Beijing, Gosan, Seoul, Osaka and Noto sites of AERONET related to this investigation, and two anonymous reviewers for useful comments and suggestions.

\section{REFERENCES}

[1] Russell, P. B., and Coauthors, 1999: Aerosol-induced radiative flux changes off the United States mid-Atlantic coast: Comparison of values calculated from Sun photometer and in situ data with those measured by airborne pyranometer. J. Geophys. Res., 104, 2289-2307.

[2] Satheesh, S. K., V. Ramanathan, X. Li-Jones, J. M. Lobert, I. A. Podgorny, J. M. Prospero, B. N. Holben, and N. G. Loeb, 1999: A model for the natural and anthropogenic aerosols over the tropical Indian Ocean derived from Indian Ocean Experiment data. J. Geophys. Res., 104, 27,421-27,440.

[3] Nakajima, T., A. Higurashi, K. Kawamoto, and J. E. Penner, 2001: A possible correlation between satellite-derived cloud and aerosol microphysical parameters. Geophys. Res. Lett., 28, 1171-1174. 
[4] IPCC, 2007 (Intergovernmental Panel on Climate Change): Climate Change 2007: The Physical Science Basis- Working Group I Contribution to the Fourth Assessment Report of the IPCC, Cambridge University Press, New York.

[5] Chuang, Y.S., 1992. On the observations of Yellow Sand (dust storms) in Korea. Atmospheric Environment 26, 2743.

[6] Zhang, X., Arimoto, R., An, Z., et al., 1993. Atmospheric trace elements over source regions for Chinese dust: concentrations, sources and atmospheric deposition on the loess plateau. Atmospheric Environment 27, 2051-2067.

[7] Park, S. U., Chang, L. S., 2000. A numerical simulation of a Yellow Sand event observed in Korea during 14-23 April. Proceedings of Trans-Pacific Conference, Washington, USA.

[8] Chun, Y., Kim, J., Choi, J.C., et al., 2001. Characteristic number size distribution of aerosol during Asian dust period in Korea. Atmospheric Environment 35, 2715-2721.

[9] Husar, R.B., Tratt, D.M., Schichtel, B.A., et al., 2001. Asian dust events of April 1998. Journal of Geophysical Research 106, 18137-18330.

[10] Carmichael, G. R., Hong, M. S., Ueda, H., Chen, L. L., Murano, K., Park, J. K., Lee, H., Kim,Y., Kang, C., Shim, S., 1997. Aerosol composition at Cheju Island, Korea, Journal of Geophysical Research 102 (D5), 6047-6061.

[11] Chen, L. L., Carmichael, G. R., Hong, M. S., Ueda, H., Shim, S., Song, C.H., Kim, Y. P., Arimoto, R., Prospero, J., Savoie, D., Murano, K., Park, J. K., Lee, H. G., Kang, C., 1997. Influences of continental outflow events on the aerosol composition at Cheju Island, South Korea, Journal of Geophysical Research 102 (D23), 28551-28574.
[12] Dubovik, O. A., Smirnov, B. N., Holben, M. B., King, M. D., Kaufman, Y. J., Eck, T. F. and Slutsker, I., 2000b. Accuracy assessments of aerosol properties retrieved from Aerosol Robotic Network (AERONET) sun and sky measurements. Journal of Geophysical Research 105, 9791-9806.

[13] Holben, B. N., Eck, T. F., Slutsker, I., Tanré, D., Buis, J. P., Setzer, A., Vermote, E., Reagan, J. A., Kaufman, Y., Nakajima, T., Lavenu, F., Jankowiak, I. and Smirnov, A., 1998. AERONET-A federated instrument network and data archive for aerosol characterization. Remote Sensing of Environment 66, 116.

[14] Smirnov, A., Holben, B. N., Eck, T. F., Dubovik O. and Slutsker I., 2000. Cloud screening and quality control algorithms for the AERONET database. Remote Sensing of Environment 73, 337349.

[15] Tanré, D., Kaufman, Y.J., Holben, B.N., et al., 2001. Climatology of dust aerosol size distribution and optical properties derived from remotely sensed data in the solar spectrum. Journal of Geophysical Research 106, 18, 205-18,217.

[16] Kim, S. W., Yoon, S. C., Jefferson, A., et al., 2005. Aerosol optical, chemical and physical properties at Gosan, Korea during Asian dust and pollution episodes in 2001. Atmospheric Environment 39, 39-50.

[17] Yu Xingna, Zhu Bin, Fan Shuxian, Yin Yan, Bu Xiaoli, 2009. Ground-based observation of aerosol optical properties in Lanzhou, China. Journal of Environmental Sciences 21, 15191524. 